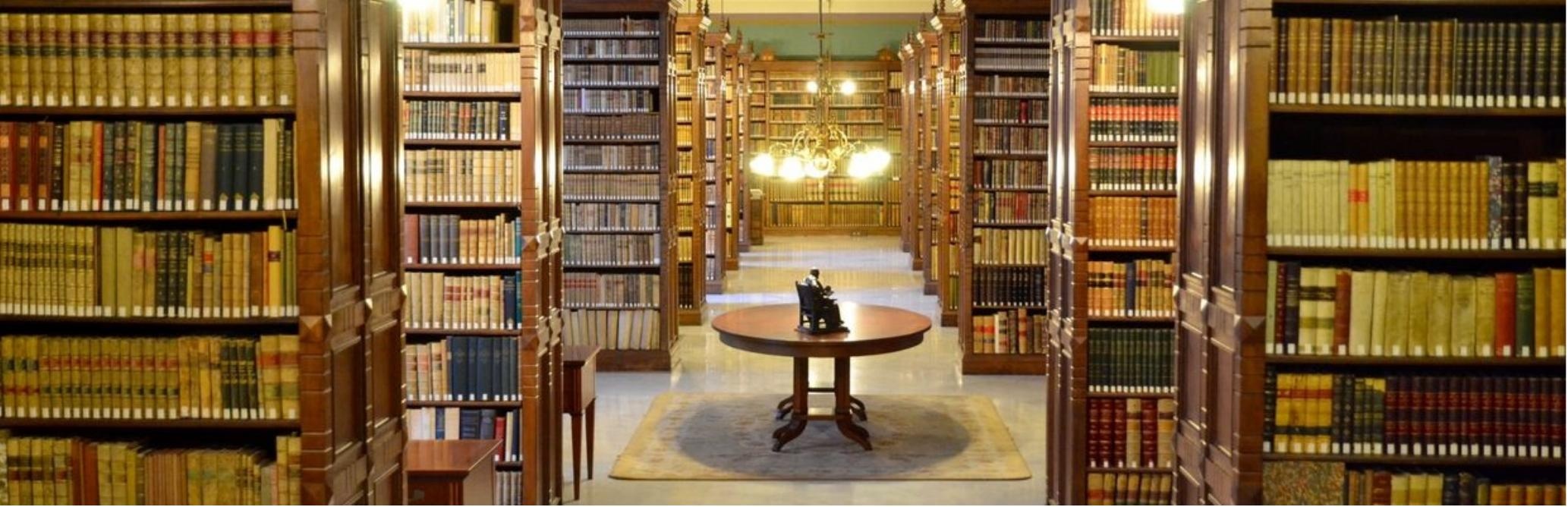




\section{JOSHA - Journal of Science Humanities and Arts Editorial Volume 6 Issue 3}

The current issue of the Josha-Journal shows again the broad spectrum of topics our articles. You will read a contribution on a novel view of cancer and its microenvironment, a touching short story, new visions in architecture and town planning as well as reflections about the audience of classical music.

The applications for the Demetrios price of 2019 should also be a reflection of the varied contributions in this current Josha-Journal issue. We would like to remind you that closing day is June $15^{\text {th }}, 2019$ !

\section{PERFORMING ARTS AND MUSIC}

Zazie-Charlotte Pfeiffer is a medical student and author of short stories. In 2013 she won the "JeanPaul Award" and in 2012 the "Tom Sawyer Award ". Zazie-Charlotte is honoured this year with the Pythagoras prize of the International Academy of Sciences, Humanities and Arts (IASHA e.V.) for her literary activity.

In her current contribution, the short story "Linda", she writes about the young career girl Linda, who believes that her life happens just like in an aquarium. Far away from human contacts and joy of life. To all surfeit, one evening late after work she misses the bus way home ... Suddenly an event happens, and Linda's life receives a turning point. But I would not like to anticipate. Read this exciting and touching story!

In his article "What is going on with the classic audience?" the concert manager Leander Hotaki reflects about the public in classical concerts. Certainly, the number of subscribers went back on the one hand, on the other hand, new concert formats and festivals would also draw a new and younger public. A lot of listeners have increased their music taste. Asides classic music they also hear songwriters like Herbert Grönemeyer and Techno. Streaming services like Spotify change the consumer behaviour. Hotaki would like that in thirty years classical music still forms an alive part of our society. Families and schools are asked to bring close classical music to children. 


\section{VISUAL ARTS, ARCHITECTURE AND DESIGN}

Bujar Q. Bajçinovci, assistant of the University of Prishtina (Kosovo), Faculty of Civil engineering and Architecture has already published articles in JoSHA. In his current and exciting contribution "Biomimicry and Biophilic design: the notions Biomimicry and Biophilie and their application in the contemporary architecture" he examines multiple and new architectural precepts.

The Biohpilic Design is a concept about the fact that every person has an innate emotional connection to other living beings. This thesis is applied to architecture and design. This means that the architecture stands in the harmony with nature and that an emotional connection to places does exist. Furthermore the community of human beings should be promoted and realistic town planning solutions should be applied.

Bajçinovci presents interesting design drafts of students for building solutions which deal with the biophilic attempt. He finally concludes, that in architecture a lasting, realistic application is necessary. The organic structures of a place and the genius loci should be respected for it.

\section{LIFE SCIENCE AND MEDICINE}

Dr. Bruce Gottlieb is a project manager of the Lady Davis Institute for Medical Research in the Jewish general hospital and exceptional professor of the department for human genetics and Ingram School of Nursing in the McGill University in Montreal, Canada. In his article "Can a Selection-Centric,Strengths-Based Approach to Cancer Treatment Help Treat or Prevent Cancer and Metastatic Disease?" he investigates in cancer, metastases and therapy. The approach of almost all current cancer therapies is essentially the same as those practiced by the Greeks and Romans, namely, to remove cancer tissues at a stage early enough to prevent cancer from overwhelming the body. While initial treatment regimens are often based on specific genomic data and are effective in many cases, they can sometimes be followed, usually after a period, by the reoccurrence of cancer as untreatable metastatic disease1, often with poor prognoses due to treatment resistance. 
Table of content: http://josha-journal.org/en/issues

Zazie-Charlotte Pfeiffer, Linda

Bruce Gottlieb, Can a Selection-Centric, Strengths-Based Approach to Cancer Treatment Help Treat or Prevent Cancer and Metastatic Disease?

Leander Hotaki, What is going on with the classic audience? - Klassik ab 70?

Bujar Q. Bajçinovci, Biomimicry and Biophilic Design: Multiple Architectural Precepts

Stephan Seiler on behalf of the JOSHA Team 